UDC 347.1

LBC 67.404.06

\title{
ON EFFECTIVENESS AND ACCESSIBILITY OF DOMESTIC REMEDIES
}

\author{
Aleksandr S. Grigoryan \\ Diplomatic Academy of the Ministry of Foreign Affairs of the Russian Federation, \\ Moscow, Russian Federation
}

\begin{abstract}
Introduction: "efficiency" and "accessibility" are the properties of domestic remedies, and if the member countries to the international treaties in the field of human rights and freedoms are not able to provide their citizens with effective and accessible remedies, they do not fulfill the obligations under the international treaties. However, these international instruments do not contain the concepts of "effective" and "accessible" national remedies, but only some of the characteristics of these properties. In this regard, the purpose of the work is to formulate the definitions of an effective and accessible domestic remedy, based on the analysis of the practice of interstate bodies for the protection of human rights and freedoms. Results: the conclusions based on what is "an effective domestic remedy "and what is "an accessible domestic remedy" are based on the analysis of the positions of the universal and regional interstate bodies for the protection of human rights and freedoms. Conclusions: as a result of the study, it is proved that these interstate authorities have similar understanding of what is "effective" and what is "available" national remedy. The features of these properties are revealed, their definitions are formulated. It is noted that the member countries to the international treaties in the field of human rights and freedoms legally represented by their authorities should give sufficient attention to studying the practice of the interstate bodies for the protection of human rights and freedoms, which reveals the essence of the properties of "efficiency" and "accessibility" of the national remedies based on the subject matter and circumstances of a particular case.

Key words: international treaty in the field of the rights and freedoms of the person, interstate body for the protection of the rights and freedoms of the person, Treaty body of the UN, European Court of human rights, InterAmerican court of Human Rights, effectiveness of domestic remedies, availability of domestic remedies.
\end{abstract}

Citation. Grigoryan A.S. On Effectiveness and Accessibility of Domestic Remedies. Legal Concept, 2018, vol. 17, no. 3, pp. 48-53. DOI: https://doi.org/10.15688/lc.jvolsu.2018.3.7

УДК 347.1

ББК 67.404 .06

\section{ОБ ЭФФЕКТИВНОСТИ И ДОСТУПНОСТИ ВНУТРИГОСУДАРСТВЕННЫХ СРЕДСТВ ПРАВОВОЙ ЗАЩИТЫ}

\author{
Александр Сергеевич Григорян \\ Дипломатическая академия Министерства иностранных дел Российской Федерации, \\ г. Москва, Российская Федерация
}

Введение: «эффективность» и «доступность» являются свойствами внутригосударственных средств правовой защиты ${ }^{1}$, и если государства-участники международных договоров в области прав и свобод человека не могут обеспечить своим гражданам эффективные и доступные средства правовой защиты, то они не выполняют обязательства по международным договорам. Вместе с тем в этих международных договорах не содержится понятий «эффективных» и «доступных» национальных средств правовой защиты, а отражены лишь отдельные признаки этих свойств. В этой связи в работе поставлена цель формулирования определений эффективного и доступного внутригосударственного средства правовой защиты на основе анализа практики межгосударственных органов по защите прав и свобод человека ${ }^{2}$. Результаты: обоснованные в работе выводы о том, что является «эффективным внутригосударственным средством правовой защиты», а что 
«доступным внутригосударственным средством правовой защиты», опираются на анализ позиций универсальных и региональных межгосударственных органов по защите прав и свобод человека. Выводы: в результате исследования обосновано, что у указанных межгосударственных органов схожее понимание того, что является «эффективным», а что «доступным» национальным средством правовой защиты. Выявлены особенности этих свойств, сформулированы их определения. Отмечено, что государствам - участникам международных договоров в области прав и свобод человека в лице их органов власти следует уделять достаточно внимания изучению практики межгосударственных органов по защите прав и свобод человека, в которой раскрывается суть свойств «эффективности» и «доступности» национальных средств правовой защиты, исходя из предмета и обстоятельств конкретного дела.

Ключевые слова: международный договор в области прав и свобод человека, межгосударственный орган по защите прав и свобод человека, договорной орган ООН; Европейский Суд по правам человека, Межамериканский суд по правам человека, эффективность внутригосударственных средств правовой защиты, доступность внутригосударственных средств правовой защиты.

Цитирование. Григорян А. С. Об эффективности и доступности внутригосударственных средств правовой защиты // Legal Concept = Правовая парадигма. - 2018. - T. 17, № 3. - C. 48-53. - DOI: https://doi.org/ 10.15688/lc.jvolsu.2018.3.7

В современном международном праве ${ }^{3}$ предъявляются высокие требования к защите прав и свобод человека. В ряде универсальных и региональных международных договоров в области прав и свобод человека, принятых после Устава ООН 1945 г. ${ }^{4}$, предусмотрены отдельные положения относительно необходимости обеспечения гражданам государств-участников эффективных и доступных внутригосударственных средств правовой защиты. Межгосударственные органы по защите прав и свобод человека, толкуя положения этих международных договоров, определяют, были ли государствами обеспечены своим гражданам эффективные и доступные национальные средства правовой защиты, и если нет, то срабатывает механизм субсидиарного (дополнительного) участия этих органов в защите и восстановлении прав и свобод человека.

Согласно ст. 8 Всеобщей декларации прав человека 1948 г. «каждый человек имеет право на эффективное восстановление в правах компетентными национальными судами в случае нарушения его основных прав, предоставляемых ему конституцией или законом» (цит. по: [12]).

Аналогичное по сути положение закреплено в ст. 13 Конвенции Совета Европы о защите прав человека и основных свобод 1950 г., согласно которой «каждый, чьи права и свободы, признанные в настоящей Конвенции, нарушены, имеет право на эффективное средство правовой защиты в государственном органе» [2], и п. 3 «а» ст. 2 Международного пакта о гражданских и политических правах 1966 г. [5].

Если обратиться к содержанию Американской конвенции о правах человека 1969 г., то в силу ст. 43 «государства-участники обязуются снабжать Межамериканскую комиссию по правам человека такой информацией, какую она может потребовать от них, о способах, которыми их национальное законодательство обеспечивает действенное применение положений настоящей Конвенции» [4].

Что касается «доступности» внутригосударственных средств правовой защиты, то, например, в Конвенции о защите прав человека и основных свобод 1950 г. это свойство не упоминается.

По смыслу ч. 1 и 2 ст. 46 Американской конвенции о правах человека 1969 г. Межамериканская комиссия по правам человека не принимает петицию или сообщение, если стороне, заявившей о нарушении ее прав, было отказано в доступе к средствам судебной защиты в национальных судебных органах или ей препятствовали в их полном использовании [4].

Тот же смысл вытекает из содержания п. 1 с) ст. 41 Международного пакта о гражданских и политических правах 1966 г., согласно которому «Комитет ООН по правам человека рассматривает переданный ему вопрос только после того, как он удостоверится, что в соответствии с общепризнанными принципами международного права все доступные внутренние средства были испробованы и исчерпаны в данном случае» [5]. 
С момента закрепления в международных договорах положений о необходимости обеспечения государствами своим гражданам эффективных и доступных средств правовой защиты началась трансформация как национального законодательства, так и практики государств по защите прав и свобод человека по «лекалам» современного международного права. Процесс этой трансформации осуществляется в соответствии с практикой межгосударственных органов по защите прав и свобод человека.

Если обратиться к практике Межамериканского суда по правам человека, то, например, в отношении права на обжалование обвинительного приговора по уголовному делу в вышестоящую судебную инстанцию Суд исходит из того, что «формального существования средства правовой защиты недостаточно - должен обеспечиваться результат или решение, на получение которого оно рассчитано» [10]. «Независимо от выбора системы средств правовой защиты и порядка оспаривания приговора государства-участники должны обеспечить возможность пересмотра ошибочного приговора» [11].

Европейский Суд по правам человека в одном из своих постановлений пришел к выводу, что «предложенные властями средства правовой защиты не являлись эффективным средством правовой защиты, которое могло бы быть использовано для предотвращения предполагаемых нарушений или их продолжения с предоставлением заявителю надлежащего и достаточного возмещения в связи с его жалобами на нарушение статьи 3 Конвенции о защите прав человека и основных свобод» [7].

Комитет ООН по правам человека в одном из своих соображений отметил, что «в соответствии с п. 3a) ст. 2 Международного пакта о гражданских и политических правах государство-участник обязано предоставить эффективное средство правовой защиты и полное возмещение ущерба лицам, чьи права, предусмотренные Пактом, были нарушены. Следовательно, государство-участник, среди прочего, обязано: а) провести тщательное и эффективное расследование в связи с фактами, представленными П.М., в частности в связи с обращением, которому она подверглась 23 но- ября 2004 г;; b) преследовать и привлечь к суду лиц, виновных в ее произвольном задержании, применении к ней пыток и домогательств, назначить виновным надлежащее наказание и довести результаты осуществления этих мер до сведения общественности; с) предоставить надлежащую компенсацию автору и обеспечить ей адекватную сатисфакцию за нарушения, от которых она пострадала, в частности возместить медицинские расходы на лечение травм, полученных при применении к ней пыток; и d) обеспечить предоставление автору необходимых и надлежащих услуг по психологической реабилитации и медицинскому лечению. Государство-участник обязано также принять меры для недопущения повторения подобных нарушений в будущем» 5 .

На основе анализа практики межгосударственных органов по защите прав и свобод человека представляется возможным охарактеризовать эффективное внутригосударственное средство правовой защиты как такое средство, применение которого способно предотвратить угрозу нарушения прав и свобод человека либо восстановить нарушенные права и свободы с учетом обстоятельств конкретного дела.

Свойство доступности внутригосударственных средств правовой защиты неразрывно связано с эффективностью этих средств.

Комитет ООН по правам человека отмечает, что «жертва грубого нарушения международных норм в области прав человека должна иметь равноправный доступ к эффективным судебным средствам правовой защиты, как это предусмотрено международным правом» ${ }^{6}$.

Межамериканский суд по правам человека, например, в отношении права на обжалование обвинительного приговора по уголовному делу в вышестоящую судебную инстанцию придерживается правовой позиции, согласно которой предоставление доступного средства правовой защиты не должно сопровождаться дополнительными сложностями, делающими право подсудимого иллюзорным [9].

Из такого подхода вытекает, что доступным средством правовой защиты является такое, к которому лицо в случае необходимости имеет право беспрепятственно прибег- 
нуть. Если же имеются проблемы, делающие невозможным использование такого средства, то оно не может считаться доступным.

Европейский Суд по правам человека в своей практике отмечает, что «п. 1 ст. 35 Конвенции о защите прав человека и основных свобод предусматривает исчерпание только тех средств правовой защиты, которые являются доступными и достаточными. Эти средства правовой защиты должны существовать с достаточной степенью определенности не только в теории, но и на практике» [8].

Анализ вышеизложенного позволяет охарактеризовать доступное внутригосударственное средство правовой защиты как такое средство, к которому лицо вправе обратиться в случае угрозы или нарушения его прав и свобод, а также существует практика его применения.

Как представляется, универсальной формулой защиты прав и свобод человека, к реализации которой следует стремиться государствам, является «обеспечить своим гражданам своевременный доступ к эффективным национальным средствам правовой защиты». Только в этом случае уместно говорить о том, что государства обеспечивают защиту прав и свобод человека в соответствии с обязательствами по международным договорам.

Примечательно, что из толкования межгосударственными органами по защите прав и свобод человека международных договоров универсального и регионального характера вытекают одинаковые подходы к тому, что является эффективным, а что доступным внутригосударственным средством правовой защиты. При этом в практике межгосударственных органов всесторонне раскрываются аспекты данных свойств средств правовой защиты.

Государствам - участникам международных договоров в области прав и свобод человека в лице их органов власти следует уделять достаточно внимания изучению практики межгосударственных органов по защите прав и свобод человека, в которой раскрывается суть «эффективности» и «доступности» национальных средств правовой защиты, исходя из предмета и обстоятельств конкретного дела. Это могло бы быть существенным подспорьем для государств в выполнении их международно-правовых обязательств и, соответственно, исключило бы необходимость субсидиарного участия в защите и восстановлении прав и свобод человека со стороны межгосударственных органов.

\section{ПРИМЕЧАНИЯ}

${ }^{1}$ Применительно к теме статьи, имеются в виду правовые средства защиты субъективных гражданских прав. Под такими средствами следует понимать «комплекс мер, включающий в себя конституционно-правовые, уголовно-правовые, гражданско-правовые, административно-правовые, процессуальные и иные средства защиты субъективных гражданских прав. Речь идет об инструментах защиты субъективных гражданских прав, как публично-правовых, так и частноправовых». См.: [13].

2 Под межгосударственными органами по защите прав и свобод человека понимаются органы, контролирующие исполнение государствами международно-правовых обязательств в сфере защиты прав и свобод человека, которые предусматриваются в международных договорах. См.: [6]. Учреждение и компетенция межгосударственных органов по защите прав и свобод человека предусмотрены универсальными и региональными международными договорами в области прав и свобод человека. Исходя из такого понимания, к межгосударственным органам по защите прав и свобод человека относятся: договорные органы ООН, Европейский Суд по правам человека, Межамериканский суд по правам человека.

${ }^{3}$ Согласно одному из мнений, начало современному международному праву было положено образованием ООН. См.: [3].

${ }^{4}$ К их числу относятся: Международный пакт о гражданских и политических правах 1966 г. и факультативные протоколы к нему; Международная конвенция о ликвидации всех форм расовой дискриминации 1965 г.; Международная конвенция о ликвидации всех форм дискриминации в отношении женщин 1979 г. и факультативный протокол к ней 1999 г.; Конвенция против пыток и других жестоких, бесчеловечных или унижающих достоинство видов обращения и наказания 1984 г; Факультативный протокол к Конвенции против пыток 2002 г; Конвенция о правах ребенка 1989 г. и факультативные протоколы к ней 2000 г.; Международная конвенция о защите прав всех трудящихся-мигрантов и членов их семей 1990 г.; Международная конвенция о правах инвалидов 2006 г; : Международная конвенция для защиты всех лиц от насильственных исчезновений 2006 г; Конвенция Совета Европы о защите прав человека и основных свобод 1950 г.; Американская конвенция о правах человека 1969 г. 
5 Соображения Комитета ООН по правам человека от 17 марта 2017 г., принятые в соответствии с п. 4 ст. 5 Факультативного протокола относительно сообщения №2245/2013 по сообщению «Пурна Мая против Непала».

6 Замечание общего порядка Комитета $\mathrm{OOH}$ по правам человека № 34 (2011) о свободе мнений и их выражения, Официальные отчеты Генеральной Ассамблеи, шестьдесят шестая сессия, Дополнение № 40, том 1 (А/66/40 (том 1)), приложение V; см. также пункт 12 основных принципов и руководящих положений, касающихся права на правовую защиту и возмещение ущерба для жертв грубых нарушений международных норм в области прав человека и серьезных нарушений международного гуманитарного права (резолюция 60/147 Генеральной Ассамблеи, приложение).

\section{СПИСОК ЛИТЕРАТУРЫ}

1. Бюллетень Верховного Суда Российской Федерации. - 1994. - № 12. - Доступ из справ.-правовой системы «КонсультантПлюс».

2. Конвенция о защите прав человека и основных свобод : (Заключена в г. Риме 04.111950 г.) // Собрание законодательства Российской Федерации. - 08.01.2001. - № 2. - Ст. 163.

3. Международное право : учебник / под ред. А. Н. Вылегжанина, Ю. М. Колосова, Ю. Н. Малеева, Р. А. Колодкина. - М. : Высшее образование : Юрайт-Издат, 2009. - 1012 с.

4. Международные акты о правах человека : сб. док. - Изд. 2. - М. : Норма : ИНФРА-М, 2002.$784 \mathrm{c}$.

5. Международный пакт о гражданских и политических правах : принят резолюцией № 2200A (XXI) Генеральной Ассамблеи от 16 декабря 1966 г. // [Веб-сайт ООН]. - Электрон. текстовые дан. - Режим доступа: http://www.un.org/ru/documents/decl conv/conventions/pactpol. - Загл. с экрана.

6. Обзор судебной практики Верховного Суда Российской Федерации № 1 (2018) : (утв. Президиумом Верховного Суда Российской Федерации 28 марта 2018 г.). - Доступ из справ.-правовой систкмы «КонсультантПлюс». - Документ опубликован не был.

7. Постановление ЕСПЧ от 22.03.2016 «Дело "Колесникович (Kolesnikovich) против Российской Федерации"». - Доступ из справ.-правовой системы «КонсультантПлюс».

8. Постановление ЕСПЧ от 24.01.2017 «Дело “J.R. против Бельгии”». - Доступ из справ.-правовой системы «КонсультантПлюс».

9. Решение Межамериканского суда по правам человека. Дело «Эррера-Юлоа против Коста-
Рики» § 164, дело «Лиакат Али Алибукс против Суринама», § 55. - Режим доступа: http://legascom. ru/notes/1783-interamerican-court-human-rights-stati.

10. Решение Межамериканского суда по правам человека. Дело «Эррера-Юлоа против КостаРики» § 161, дело «Лиакат Али Алибукс против Суринама» § 52. - Режим доступа: http://legascom.ru/ notes/1783-interamerican-court-human-rights-stati.

11. Решение Межамериканского суда по правам человека. Дело «Касо Мухамед против Аргентины» § 100, дело «Лиакат Али Алибукс против Суринама» § 86. - Режим доступа: http://legascom.ru/ notes/1783-interamerican-court-human-rights-stati.

12. Российская газета. - 1995. - 05 апр. (№ 67).

13. Шершень, Т. В. Гражданско-правовые средства защиты прав и интересов потребителей / Т. В. Шершень // Вестник Пермского университета. Юридические науки. - 2012. - № 3. - Доступ из справ.-правовой системы «КонсультантПлюс».

\section{REFERENCES}

1. Byulleten Verkhovnogo Suda Rossiyskoy Federatsii [Bulletin of the Supreme Court of the Russian Federation], 1994, no. 12. Access from Reference Legal System 'KonsultantPlyus'.

2. Konventsiya o zashchite prav cheloveka i osnovnykh svobod: (Zaklyuchena vg. Rime 04.11 1950g.) [Convention for the Protection of Human Rights and Fundamental Freedoms: (Concluded in Rome on 4 November 1950)]. Sobranie zakonodatelstva Rossiyskoy Federatsii [Collected Legislation of the Russian Federation], 2001, no. 2, art. 163.

3. Vylegzhanin A.N., Kolosov Yu.M., Maleev Yu.N., Kolodkin R.A., eds. Mezhdunarodnoe pravo [International Law]. Moscow, Vysshee obrazovanie Publ.; Yurayt-Izdat Publ., 2009. 1012 p.

4. Mezhdunarodnye akty o pravakh cheloveka: sb. dok. [International Acts on Human Rights: Collected Documents]. Moscow, Norma; INFRA-M Publ., 2002. 784 p.

5. Mezhdunarodnyy pakt o grazhdanskikh i politicheskikh pravakh: prinyat rezolyutsiey № 2200A (XXI) Generalnoy Assamblei ot 16 dekabrya 1966 g. [International Covenant on Civil and Political Rights: Adopted by General Assembly Resolution No. 2200A (XXI) of 16 December 1966]. UN Website. URL: http:// www.un.org/ru/documents/decl_conv/conventions/ pactpol.

6. Obzor sudebnoy praktiki Verkhovnogo Suda Rossiyskoy Federatsii № 1 (2018): (utv. Prezidiumom Verkhovnogo Suda Rossiyskoy Federatsii 28 marta 2018 g.) [Review of the Judicial Practice of the Supreme Court of the Russian Federation No. 1 (2018): (Approved by the Presidium of the Supreme Court of 
А.С. Григорян. Об эффективности и доступности внутригосударственных средств правовой защиты

the Russian Federation on March 28, 2018)]. Access from Reference Legal System 'KonsultantPlyus'.

7. Postanovlenie ESPCh ot 22.03.2016 «Delo "Kolesnikovich (Kolesnikovich) protiv Rossiyskoy Federatsii"” [Decision of the European Court of Human Rights of 22 March 2016 'Case "Kolesnikovich vs. the Russian Federation"']. Access from Reference Legal System 'KonsultantPlyus'.

8. Postanovlenie ESPCh ot 24.01.2017 «Delo "J.R. protiv Belgii"” [Decision of the European Court of Human Rights of 24 January 2017 'Case "J.R. against Belgium"']. Access from Reference Legal System 'KonsultantPlyus'.

9. Reshenie Mezhamerikanskogo suda po pravam cheloveka. Delo «Errera-Yuloa protiv KostaRiki» 164 , delo «Liakat Ali Alibuks protiv Surinama», $\S 55$ [Decision of the Inter-American Court of Human Rights. Case 'Herrera-Yuloa vs. Costa Rica', $\S 164$; Case 'Liaquat Ali Alibux vs. Suriname', § 55]. URL: http://legascom.ru/notes/1783-interamericancourt-human-rights-stati.
10. Reshenie Mezhamerikanskogo suda po pravam cheloveka. Delo «Errera-Yuloa protiv Kosta-Riki» $\S 161$, delo «Liakat Ali Alibuks protiv Surinama» $\S 52$ [Decision of the Inter-American Court of Human Rights. Case 'Herrera-Yuloa vs. Costa Rica', § 161; Case 'Liaquat Ali Alibux vs. Suriname’ § 52]. URL: http://legascom.ru/ notes/1783-interamerican-court-human-rights-stati.

11. Reshenie Mezhamerikanskogo suda po pravam cheloveka. Delo «Kaso Mukhamed protiv Argentiny» $\S 100$, delo «Liakat Ali Alibuks protiv Surinama» $\S 86$ [Decision of the Inter-American Court of Human Rights. Case 'Kaso Muhamed vs. Argentina' § 100; Case 'Liaqat Ali Alibux vs. Suriname’ § 86]. URL: http://legascom.ru/ notes/1783-interamerican-court-human-rights-stati.

12. Rossiyskaya gazeta, 1995, no. 67 (April 5).

13. Shershen T.V. Grazhdansko-pravovye sredstva zashchity prav i interesov potrebiteley [Civil and Legal Remedies for Protecting Consumers' Rights and Interests]. Vestnik Permskogo universiteta. Yuridicheskie nauki, 2012, no. 3. Access from Reference Legal System 'KonsultantPlyus'.

\section{Information about the Author}

Aleksandr S. Grigoryan, Postgraduate Student, Department of International Law, Diplomatic Academy of the Ministry of Foreign Affairs of the Russian Federation; Attaché of the Second European Department of the Ministry of Foreign Affairs of the Russian Federation, Smolenskaya-Sennaya Sq., 32/34, 119200 Moscow, Russian Federation, grigoryan84@inbox.ru.

\section{Информация об авторе}

Александр Сергеевич Григорян, аспирант кафедры международного права, Дипломатическая академия Министерства иностранных дел Российской Федерации; Атташе Второго Европейского департамента, МИД России, Смоленская-Сенная пл., 32/34, 119200 г. Москва, Российская Федерация, grigoryan84@inbox.ru. 